\title{
Utilization of amplicon-based targeted sequencing panel for the massively parallel sequencing of sporadic hearing impairment patients from Saudi Arabia
}

Ashraf Dallol ${ }^{1,2^{*}}$, Kamal Daghistani ${ }^{2}$, Aisha Elaimi ${ }^{1}$, Wissam A. Al-Wazani ${ }^{1}$, Afaf Bamanie ${ }^{3}$, Malek Safiah ${ }^{4}$, Samira Sagaty ${ }^{5}$, Layla Taha ${ }^{6}$, Rawabi Zahed ${ }^{1}$, Osama Bajouh ${ }^{1,3}$, Adeel Gulzar Chaudhary ${ }^{2}$, Mamdooh Abdullah Gari ${ }^{2}$, Rola Turki ${ }^{3}$, Mohammed Hussein Al-Qahtani ${ }^{2}$ and Adel Mohammed Abuzenadah 1,2,6

From 3rd International Genomic Medicine Conference

Jeddah, Saudi Arabia. 30 November - 3 December 2015

\begin{abstract}
Background: Hearing Impairment (HI) can have genetic or environmental causes and in some cases, an interplay of both. Genetic causes are difficult to determine as mutations in more than 90 genes have been shown recently to be responsible for HI. Providing a genetic diagnostic test for $\mathrm{HI}$ is therefore a challenge especially for ethnic groups where GJB2 mutations are shown to be rare.

Results: Here we show the design and implementation of an amplicon-based targeted sequencing panel that allows the simultaneous sequencing of $87 \mathrm{HI}$ genes. Mutations identified included known pathogenic mutations and novel variants with unknown significance. The diagnostic rate of this panel is $28 \%$ when only pathogenic variants were reported. However, an additional $28 \%$ harbored recurrent combinations of novel or rare single nucleotide variants in the OTOF or PCDH15 genes. Such combinations were not identified in healthy individuals.

Conclusions: Targeted sequencing approach is a very useful strategy for the identification of mutations affecting the $\mathrm{HI}$ genes because of its relatively fast turn-around time and cost effectiveness compared to whole-exome sequencing. Further novel or rare variants could be identified by implementing a large-scale screening of HI using our panel which will eventual lead to a higher diagnostic rate.
\end{abstract}

Keywords: Hearing impairment, NGS, Targeted sequencing, Saudi Arabia

\section{Background}

Hearing loss is a common disease found in many populations worldwide ast is estimated that at least $50 \%$ of prelingual hearing impairment $(\mathrm{HI})$ is heritable either as a phenotype in many syndromes or in a non-syndromic fashion [1]. The heritability of HI follows all types of

\footnotetext{
* Correspondence: adallol@kau.edu.sa

${ }^{1}$ Center of Innovations in Personalized Medicine, King Abdulaziz University,

P.O. Box 80216, Jeddah 21589, Kingdom of Saudi Arabia

${ }^{2}$ Center of Excellence in Genomic Medicine Research, King Abdulaziz

University, Jeddah, Kingdom of Saudi Arabia

Full list of author information is available at the end of the article
}

Mendelian inheritance and can be passed down to subsequent generations in autosomal/X-linked recessive or dominant manner. The large number of genes required for hearing causes such complexity in inheritance patterns. Mutations in any one of such genes is sufficient to cause various degrees of HI. Mutations in GJB2, SLC26A4, MYO15A, OTOF, and CDH23 genes are the most frequent causes of autosomal recessive $\mathrm{HI}$ at varying degrees [2]. On average, about $50 \%$ of any given cohort of autosomal recessive $\mathrm{HI}$ will have a pathogenic mutation in the GJB2 gene [3-6]. However, the frequency of HI-causing GJB2 gene mutations is 
population-dependent as it is most predominant $\mathrm{HI}$ gene in Caucasians and rather rare in South East Asians or Arab populations [7, 8].

The prevalence of the 35delG mutation in GJB2 gene in Caucasians has allowed its use as a genetic screening tool for early detection and diagnosis of $\mathrm{HI}$ in newborns. However, such a test is not applicable in other ethnic groups due to its rarity. In fact, since over 90 genes have now been shown to be associated with HI, it is not feasible to offer classical genetic testing for $\mathrm{HI}$ in many populations. The advent of massively parallel sequencing and whole-exome sequencing (WES) led to a rapid increase in the rate of identifying the genetic determinants of HI [9]. In order to achieve such aim, whole-exome sequencing is applied to several members of the affected family in order to identify the genetic cause (s) of HI amongst hundreds of candidate variants $[10,11]$. Furthermore, WES is expensive and time-consuming and it is not yet amenable for largescale screening of $\mathrm{HI}$ that will invariably include sporadic cases. Amplicon-based targeted sequencing is a cost-effective tool to precede WES that will allow the focused sequencing of relevant HI genes and improve the diagnostic rate of such tests $[12,13]$.

In this study, we designed and validated a custommade amplicon-based targeted sequencing panel for HI that allows the simultaneous sequencing of 87 genes shown previously to be associated with various forms of HI.

\section{Materials and methods Patients}

Samples from $25 \mathrm{HI}$ patients were collected following the appropriate local ethical protocols and guidelines from the Audiology clinic at King Abdulziz University Hospital in Jeddah, Saudi Arabia or the Audiology department of the King Fahad General Hospital, Jeddah Institute for Speech and Hearing (JISH) as well as AlAmal secondary school for the hearing impaired, Jeddah, Saudi Arabia. All samples were selected according to the diagnosis of bilateral severe-to-profound hearing impairment as determined by audiologists in the study team. The patients ages ranged from 4 to 22 years old. Control samples were obtained from non-HI patients and aged 18-40 years old. DNA was extracted from peripheral blood DNA using the standard protocol of the QIAGEN Blood DNA Extraction kit. The study was approved by the local ethical committee.

\section{Targeted sequencing of deafness genes}

Eighty-seven genes involved in HI were determined using the Deafness Variation Database (http://deafnessvariation database.org). The gene names were submitted for primer design to the http://Ampliseq.com website were a targeted sequencing panel was designed and manufactured by Life Technologies. Barcoded Ampliseq libraries (2 pools) were prepared using the Ampliseq Library kit 2.0 from $10 \mathrm{ng}$ of DNA (concentration determined using the Qubit ${ }^{\text {tux }}$ fluorometer). Templated spheres were prepared using $100 \mathrm{pM}$ of DNA from each library using the Ion OneTouch 2.0 machine. Template-positive spheres from the barcoded libraries were multiplexed and loaded onto Ion chips 316 or 318 version 2.0 and sequencing was performed using the Ion Sequencing 200 v2 kit from Life Technologies. Processing of the Ion Torrent Personal Genome Machine (PGM) runs was achieved with the Torrent Suite version 4.4.3. The Coverage Analysis plugin was used to calculate coverage efficiency and read depth. The Ion Reporter v4.6 was used to identify and annotate variants.

\section{DNA sequencing using the sanger method}

Pathogenic and novel variants were confirmed by custom oligonucleotide primers designed to flank the variant of interest in order to prepare PCR fragments for sequencing. PCR was performed at optimal condition for each primer pair and products were purified using ethanol precipitation. DNA sequencing was performed using the BigDye v. 3.1 and analyzed on the DNA Analyzer 3500 from Life Technologies. Additionally, TaqMan ${ }^{\circ}$ SNP genotyping assays, either customdesigned or pre-made, were utilized in the validation process or screening further cases.

\section{Results}

We have adopted the amplicon-based targeted sequencing approach in order to develop a more efficient method for the detection of mutations affecting the deafness genes. In this approach, sequencing is limited to the genes known or has been previously demonstrated to play a role in causing HI. (Table 1) lists the genes included in this panel obtained from the deafness variation database (http://deafnessvariationdatabase.org).

Eighty-seven genes were selected and custom primers were designed and manufactured through the ampliseq portal (http://ampliseq.com). The design resulted in an excellent coverage of $97.42 \%$ generating 2697 amplicons with a size range of 125-275 bp in two pools and generating $500.44 \mathrm{~kb}$ of DNA sequence. Identified variants were confirmed by Sanger sequencing.

We have managed to screen 25 individuals affected with HI using this approach. Additionally, we have screened samples from 6 healthy volunteers with no history of $\mathrm{HI}$ as a control. Seven patients were found to have pathogenic (according to clinvar database) mutations affecting OTOF, MYO7A, TMC1 and GJB3 genes (Table 2; Fig. 1). The homozygous c.2239C > A change in the OTOF gene causes a premature termination of the 
Table 1 Genes included in our HI panel

\begin{tabular}{|c|c|c|c|c|c|c|c|}
\hline Gene & Coverage (\%) & Gene & Coverage (\%) & Gene & Coverage (\%) & Gene & Coverage (\%) \\
\hline ACTG1 & 56.62 & GIPC3 & 98.9 & OTOA & 97.82 & TSPEAR & 97.54 \\
\hline AlFM1 & 100 & GJB2 & 100 & OTOF & 95.41 & USH1C & 97.21 \\
\hline ALMS1 & 99.25 & GJB3 & 78.86 & OTOG & 98.3 & USH1G & 100 \\
\hline ATP2B2 & 100 & GJB6 & 100 & OTOGL & 99.71 & USH2A & 98.87 \\
\hline CABP2 & 100 & GPR98 & 99.42 & $\mathrm{P} 2 \mathrm{R} \times 2$ & 80.21 & WFS1 & 97.63 \\
\hline CACNA1D & 100 & GPSM2 & 100 & PCDH15 & 98.27 & WHRN & 100 \\
\hline CATSPER2 & 100 & GRHL2 & 100 & PNPT1 & 97.07 & MIR-182 & 100 \\
\hline CCDC50 & 100 & GRXCR1 & 100 & POU3F4 & 100 & MIR-183 & 66 \\
\hline $\mathrm{CDH} 23$ & 99.55 & HGF & 99.4 & POU4F3 & 100 & MIR96 & 100 \\
\hline CEACAM16 & 94.39 & |LDR1 & 95.7 & PRPS1 & 100 & DFNB59 & 100 \\
\hline $\mathrm{ClB} 2$ & 95.87 & KCNQ1 & 86.04 & PTPRQ & 97.5 & ESRRB & 91.35 \\
\hline CLDN14 & 88.36 & KCNQ4 & 87.25 & $\mathrm{RDX}$ & 100 & TMPRSS3 & 100 \\
\hline CLPP & 99.78 & LARS2 & 98.63 & SERPINB6 & 97.18 & & \\
\hline CLRN1 & 100 & LHFPL5 & 100 & SIX1 & 95.77 & & \\
\hline $\mathrm{COCH}$ & 100 & LOXHD1 & 99.72 & SLC26A4 & 100 & & \\
\hline COL11A2 & 99.9 & LRTOMT & 100 & SLC26A5 & 100 & & \\
\hline CRYL1 & 99.04 & MARVELD2 & 100 & SMAD4 & 100 & & \\
\hline CRYM & 100 & MSRB3 & 100 & SMPX & 100 & & \\
\hline DFNA5 & 100 & MYH14 & 97.53 & STRC & 99.82 & & \\
\hline DIABLO & 100 & MYH9 & 98.11 & TECTA & 98.28 & & \\
\hline DIAPH1 & 98.49 & MYO15 & 94.22 & TJP2 & 98.17 & & \\
\hline DSPP & 80.44 & MYO1A & 100 & TMC1 & 96.54 & & \\
\hline ESPN & 73.28 & MYO3A & 100 & TMIE & 79.84 & & \\
\hline EYA1 & 100 & MYO6 & 100 & TPRN & 93.57 & & \\
\hline EYA4 & 100 & MYO7A & 98.72 & TRIOBP & 92.17 & & \\
\hline
\end{tabular}

protein at p. Glu747Ter. This mutation was identified in a brother and sister suffering from severe to profound HI. The homozygous IVS5 + $1 \mathrm{G}>\mathrm{A}$ change in the MYO7 gene is a mutation affecting the $5^{\prime}$ splice site and was found in a brother and sister with severe to profound $\mathrm{HI}$ in our screen. The p. Arg830His in MYO7A gene is a very rare SNP (single nucleotide polymorphisms) with a reported minor allele frequency of 0.0001556 and classified as likely pathogenic by the ClinVar database (http://www.ncbi.nlm.nih.gov/clinvar/).
This variant was identified in two of our patients with severe to profound $\mathrm{HI}$, albeit one of the patient harbored the mutation in a heterozygous state thus could not sufficiently account for the disease. The c.100C > T, p. Arg34Ter variant in the TMC1 gene is a pathological change according to ClinVar database. The c.100C > T, p. Arg34Ter homozygous change in the TMC1 gene causes the premature termination of the protein and found only in one patient. The rs74315318 SNP is c.547G > A change causing a p. Glu183Lys alteration in

Table 2 Pathogenic mutations identified in our cohort

\begin{tabular}{lllllll}
\hline Position & genotype & gene & transcript & coding & protein & diagnosis \\
\hline chr2:26700593 & A/A & OTOF & NM_194248 & c.2239G > T & p. Glu747Ter & Severe to profound \\
chr1:35250910 & G/A & GJB3 & NM_001005752 & c.547G > A & p. Glu183Lys & Severe to profound \\
chr11:76890902 & A/A & MYO7A & NM_000260 & c.2489G > A & p. Arg830His & Severe to profound \\
chr11:76867138 & A/A & MYO7A & NM_000260 & c.470 + 1G > A & IVS5 + 1G > A & Severe to profound \\
chr9:75309494 & T/T & TMC1 & NM_138691 & c.100C > T & p. Arg34Ter & Severe to profound \\
\hline
\end{tabular}




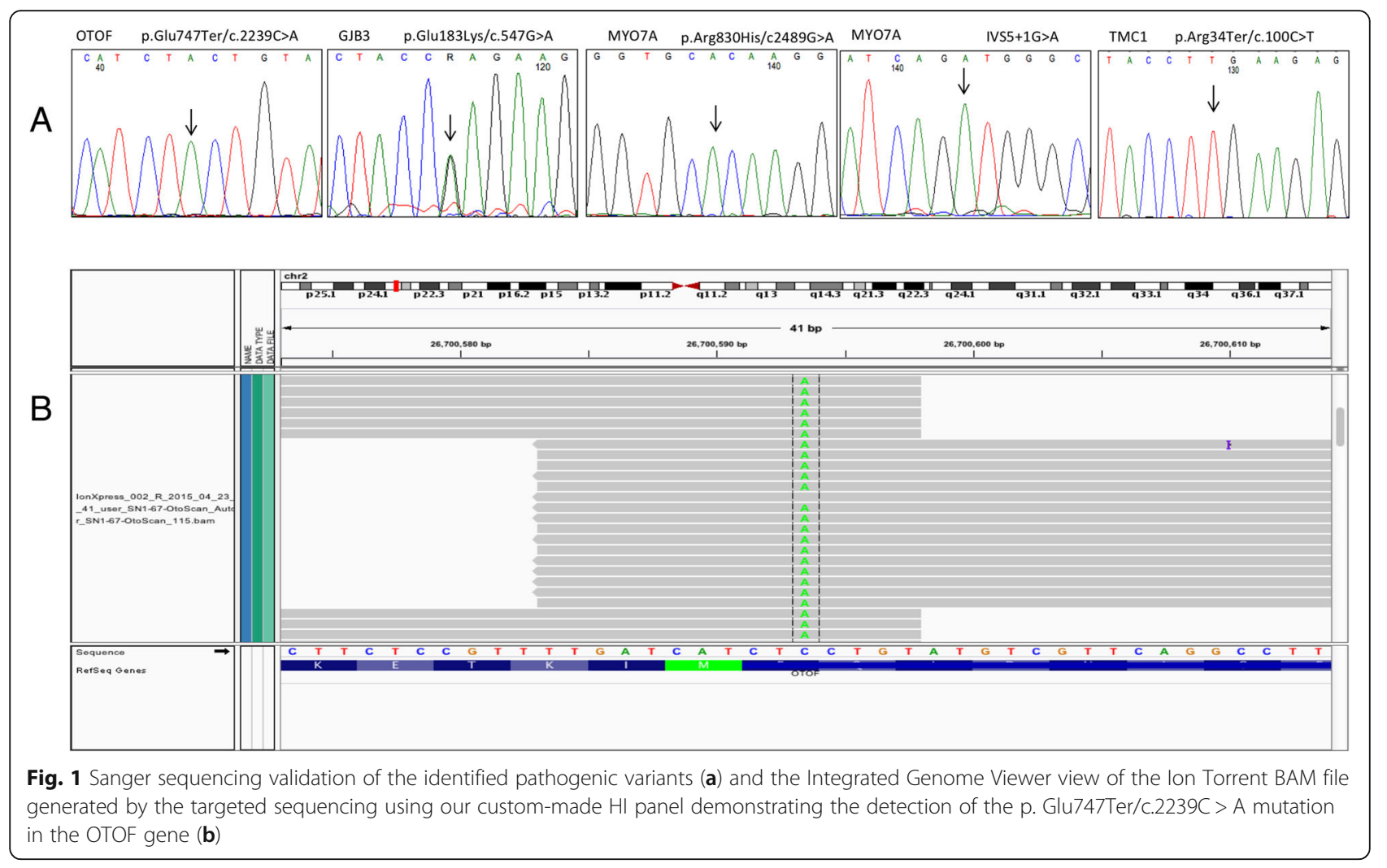

the GJB3 gene. This variant is reported to be pathological in an autosomal dominant fashion in the ClinVar database.

Although we could not identify additional known pathogenic mutations in our cohort, we have identified 7 patients with a possible genetic aberration underlying their HI. In these patients, two novel or rare SNVs were identified affecting the same gene (Table 3). In particular, in the OTOF and PCDH15 genes. The rare damaging SNPs [minor allele frequency (MAF) of 0.001 and 0.006 , respectively] identified in combination in the PCDH15 gene were recurrent in 3 unrelated patients. Furthermore, we have designed custom-made $\mathrm{TaqMan}^{\circ}$ SNP genotyping assays targeting such mutations in order to test whether the variants identified in this screen recur in other unrelated patients. Interestingly, the combination identified by the panel was not found in 80 additional $\mathrm{HI}$ patients or non-HI controls.

\section{Discussion and conclusions}

We have screened $25 \mathrm{HI}$ patients using a custom-made targeted sequencing panel to simultaneously screen 87 genes known to play a role in HI. Known pathogenic mutations were identified in 7 patients which gives a diagnostic rate of $28 \%$. The rs74315318 SNP is a c.547G > A change causing a p. Glu183Lys alteration in the GJB3 protein. This variant is reported to be pathological in the ClinVar database [14] according to a published report of its identification in Chinese families with autosomal dominant hearing loss [15]. We have also identified a homozygous c.2239C > A change in the OTOF gene causing premature termination of protein at p. Glu747Ter. This mutation was identified in a brother and sister suffering from severe to profound $\mathrm{HI}$. Although not reported in the dbSNP, this variant was previously identified in a Libyan family [16]. The c.100C > $\mathrm{T}$, p. Arg34Ter homozygous change in the TMC1 gene causes the premature termination of the protein and has been previously reported in more than 23 probands with sensorineural hearing loss [17-19]. We have identified this variant in the homozygous state in one patient with profound $\mathrm{HI}$. The homozygous IVS5 + 1G > A change in the MYO7A gene is a mutation affecting the $5^{\prime}$ splice site and was found in a brother and sister with severe to profound HI in our screen. This mutation was reported only once previously in a Tunisian family enrolled in a study of Usher 1B syndrome [20]. The p. Arg830His in the MYO7A gene is a very rare SNP with a minor allele frequency of 0.0001556 as reported by the exome aggregation consortium (ExAC) data set [21]. This variant was identified in two of our patients with profound HI.

Genetic factors underlying HI patients from Saudi Arabia are not fully elucidated and therefore, other mutations may play a role. For example, we have identified 
Table 3 Novel or rare variants identified in our screen

\begin{tabular}{|c|c|c|c|c|c|c|c|c|c|c|c|}
\hline Case & Position & ref & genotype & MAF & gene & protein & coding & SIFT (score) & polyphen & dbsnp & transcript \\
\hline \multirow[t]{2}{*}{147} & chr2:26689695 & G & $\mathrm{G} / \mathrm{C}$ & NA & OTOF & p. Pro1463Ala & c. $4387 C>G$ & $\begin{array}{l}\text { Damaging } \\
(0)\end{array}$ & $\begin{array}{l}\text { Probably } \\
\text { damaging } \\
(0.965)\end{array}$ & Novel & NM_194248.2 \\
\hline & chr2:26750782 & G & $\mathrm{G} / \mathrm{A}$ & 0.008 & OTOF & p. Arg49Trp & c. $145 C>T$ & $\begin{array}{l}\text { Damaging } \\
(0)\end{array}$ & $\begin{array}{l}\text { Probably } \\
\text { damaging (1) }\end{array}$ & rs61746568 & \\
\hline \multirow[t]{2}{*}{144} & chr2:26695500 & A & $\mathrm{A} / \mathrm{C}$ & 0.009 & OTOF & p. Cys1251Gly & c. $3751 \mathrm{~T}>\mathrm{G}$ & $\begin{array}{l}\text { Tolerated } \\
(0.46)\end{array}$ & Benign (0) & rs41288773 & NM_194248.2 \\
\hline & chr2:26750782 & G & $\mathrm{G} / \mathrm{A}$ & 0.008 & OTOF & p. Arg49Trp & c. $145 C>T$ & $\begin{array}{l}\text { Damaging } \\
(0)\end{array}$ & $\begin{array}{l}\text { Probably } \\
\text { damaging (1) }\end{array}$ & rs61746568 & \\
\hline \multirow[t]{2}{*}{151} & chr2:26696374 & C & $C / T$ & 0.006 & OTOF & p. Arg1157Gln & c. $3470 \mathrm{G}>\mathrm{A}$ & $\begin{array}{l}\text { Tolerated } \\
\text { (1) }\end{array}$ & $\begin{array}{l}\text { Probably } \\
\text { damaging (1) }\end{array}$ & rs56054534 & NM_194248.2 \\
\hline & chr2:26781384 & C & $C / T$ & 0 & OTOF & p. $\operatorname{Arg} 19 \mathrm{Gln}$ & c. $56 \mathrm{G}>\mathrm{A}$ & $\begin{array}{l}\text { Damaging } \\
(0.006)\end{array}$ & $\begin{array}{l}\text { Probably } \\
\text { damaging (1) }\end{array}$ & rs200316189 & \\
\hline \multirow[t]{2}{*}{197} & chr10:55779975 & C & $C / A$ & 0.001 & PCDH15 & p. Ala915Ser & $c .2743 G>T$ & $\begin{array}{l}\text { Damaging } \\
(0.05)\end{array}$ & $\begin{array}{l}\text { Probably } \\
\text { damaging (1) }\end{array}$ & rs139175351 & NM_001142763.1 \\
\hline & chr10:55782743 & A & $A / G$ & 0.006 & PCDH15 & p. lle817Thr & c.2450 T>C & $\begin{array}{l}\text { Damaging } \\
(0.023)\end{array}$ & $\begin{array}{l}\text { Probably } \\
\text { damaging } \\
(0.998)\end{array}$ & rs61731363 & \\
\hline \multirow[t]{2}{*}{350} & chr10:55779975 & C & $C / A$ & 0.001 & PCDH15 & p. Ala915Ser & c. $2743 \mathrm{G}>\mathrm{T}$ & $\begin{array}{l}\text { Damaging } \\
(0.05)\end{array}$ & $\begin{array}{l}\text { Probably } \\
\text { damaging (1) }\end{array}$ & rs139175351 & NM_001142763.1 \\
\hline & chr10:55782743 & A & $A / G$ & 0.006 & PCDH15 & p. lle817Thr & c. $2450 \mathrm{~T}>\mathrm{C}$ & $\begin{array}{l}\text { Damaging } \\
(0.023)\end{array}$ & $\begin{array}{l}\text { Probably } \\
\text { damaging } \\
(0.998)\end{array}$ & rs61731363 & \\
\hline \multirow[t]{2}{*}{888} & chr10:55779975 & C & $\mathrm{C} / \mathrm{A}$ & 0.001 & PCDH15 & p. Ala915Ser & c. $2743 G>T$ & $\begin{array}{l}\text { Damaging } \\
(0.05)\end{array}$ & $\begin{array}{l}\text { Probably } \\
\text { damaging (1) }\end{array}$ & rs139175351 & NM_001142763.1 \\
\hline & chr10:55782743 & A & $A / G$ & 0.006 & PCDH15 & p. lle817Thr & c. $2450 \mathrm{~T}>\mathrm{C}$ & $\begin{array}{l}\text { Damaging } \\
(0.023)\end{array}$ & $\begin{array}{l}\text { Probably } \\
\text { damaging } \\
(0.998)\end{array}$ & rs61731363 & \\
\hline \multirow[t]{2}{*}{873} & chr3:121712010 & A & $A / G$ & NA & ILDR1 & p. Val529Ala & c.1586 T>C & $\begin{array}{l}\text { Tolerated } \\
\text { (1) }\end{array}$ & Benign (0.39) & Novel & NM_001199799.1 \\
\hline & chr7:129414567 & $C$ & $C / T$ & NA & MIR96 & & & & & rs370173345 & NR_029512.1 \\
\hline
\end{tabular}

in this study a $\mathrm{C}>\mathrm{T}$ change in the sequence of the MIR96 microRNA which has been recently shown to play a role in hearing [22]. This SNP is extremely rare and according to the ExAC browser [21] carries a minor allele frequency of 0.0001428 . This mutation is also conserved and lies close to the $+57 \mathrm{~T}>\mathrm{C}$ mutation recently shown to cause autosomal dominant hearing loss in Italian families by altering pre-miRNA processing [23]. This variant was identified in a patient with severe to profound hearing loss. In addition, we have identified a patient that harbored a rare rs369424114 variant in the MYO7A gene. This variant has a minor allele frequency of 0.0006688 and found predominantly in the south Asian population [21].

An interesting observation in this cohort is the coexistence of two damaging variants of PCDH15 gene in 3 unrelated patients. The reported MAF for the p. Ala915Ser and the p. Ile817Thr variants is 0.001 and 0.006, respectively. Additionally, a novel OTOF gene variant, p. Pro1463Ala, co-existed with another rare OTOF variant, p. Arg49Trp, $(\mathrm{MAF}=0.008)$ in one patient. Another patient harbored the latter variant with the rare p. Cys1251Gly variant $(\mathrm{MAF}=0.009)$ affecting the same gene. A third unrelated patient harbored the rare p. Arg1157Gln variant in the OTOF gene $(\mathrm{MAF}=$ 0.001) as well as another rare variant, p. Arg19Gln, affecting the same gene. The co-existence of such rare or novel variants may reflect a new state of pathogenicity of single nucleotide variants affecting the OTOF and PCDH15 genes in our cohort.

In conclusion, our study shows that targeted sequencing approach is a very useful strategy for the identification of mutations affecting the HI genes. However, further work is necessary to identify and characterize novel variants in each ethnic group. Targeted sequencing is relatively fast and cost effective compared to wholeexome sequencing which renders possible the screening of large cohorts of sporadic HI patients. Additionally, targeted sequencing combined with next generation sequencing can be utilized as an aid for genetic counseling of families affected with hearing impairment. Furthermore, such test can be applied as a premarital screening 


\section{tool at a national level in order to significantly reduce the burden of $\mathrm{HI}$ on the society.}

\section{Abbreviations}

ExAC: Exome aggregation consortium; HI: Hearing impairment; MAF: Minor allele frequency; MPS: Massively parallel sequencing; NSHL: Non-syndromic hearing loss; PGM: Personal genome machine; SNPs: Single nucleotide polymorphisms; WES: Whole-exome sequencing

\section{Acknowledgements}

The authors acknowledge the excellent technical assistance of Najla Filimban, Maram Amin, Fatima Gazzaz and Shireen Turkistani.

\section{Declaration}

This article has been published as part of BMC Medical Genetics Volume 17 Supplement 1, 2016: Proceedings of the 3rd International Genomic Medicine Conference: medical genetics. The full contents of the supplement are available online at http://bmcmedgenet.biomedcentral.com/articles/ supplements/volume-17-supplement-1.

\section{Funding}

Funding by the King Abdulaziz City for Science and Technology (KACST) is acknowledged through project no. ARP-30-304. Publication fees for this article are paid by the Center of Excellence in Genomic Medicine Research (CEGMR), King Abdulaziz University, Jeddah, Kingdom of Saudi Arabia.

\section{Availability of data and materials}

Not applicable.

\section{Authors' contributions}

$K D, A B, M S, S S, R T, O B$ provided samples and clinical diagnosis. AE, WA, LT, RZ provided technical support. AGC, MAG, MHA aided in the design and administration of this study. AMA provided logistical support and critical discussion of this manuscript. $A D$ analyzed the data and wrote the manuscript. All read and approved the final manuscript.

\section{Competing interests}

The authors declare that they have no competing interests.

\section{Consent for publication}

Not applicable.

\section{Ethics approval and consent to participate}

This study was approved by the Research Committee of the Biomedical Ethics Unit, Faculty of Medicine, King Abdulaziz University, Jeddah, Saudi Arabia.

\section{Author details}

'Center of Innovations in Personalized Medicine, King Abdulaziz University, P.O. Box 80216, Jeddah 21589, Kingdom of Saudi Arabia. ${ }^{2}$ Center of Excellence in Genomic Medicine Research, King Abdulaziz University, Jeddah, Kingdom of Saudi Arabia. ${ }^{3}$ King Abdulaziz University Hospital, King Abdulaziz University, Jeddah, Kingdom of Saudi Arabia. ${ }^{4}$ Jeddah Institute for Speech and Hearing, Jeddah, Kingdom of Saudi Arabia. ${ }^{5}$ King Fahad General Hospital, Jeddah, Kingdom of Saudi Arabia. ${ }^{6}$ Faculty of Applied Medical Sciences, King Abdulaziz University, Jeddah, Kingdom of Saudi Arabia.

\section{Published: 10 October 2016}

\section{References}

1. Petersen MB, Willems PJ. Non-syndromic, autosomal-recessive deafness. Clin Genet. 2006:69(5):371-92

2. Hereditary Hearing Loss Homepage [http://hereditaryhearingloss.org]

3. Abe S, Usami S, Shinkawa H, Kelley PM, Kimberling WJ. Prevalent connexin 26 gene (GJB2) mutations in Japanese. J Med Genet. 2000;37(1):41-3.

4. Abidi O, Boulouiz R, Nahili $H$, Ridal M, Alami MN, Tlili A, Rouba H, Masmoudi S, Chafik A, Hassar M, et al. GJB2 (connexin 26) gene mutations in Moroccan patients with autosomal recessive non-syndromic hearing loss and carrier frequency of the common GJB2-35delG mutation. Int J Pediatr Otorhinolaryngol. 2007;71(8):1239-45. Epub 2007 Jun 1235.

5. Estivill X, Govea N, Barcelo E, Badenas C, Romero E, Moral L, Scozzri R, D'Urbano L, Zeviani M, Torroni A. Familial progressive sensorineural deafness is mainly due to the mtDNA A1555G mutation and is enhanced by treatment of aminoglycosides. Am J Hum Genet. 1998;62(1):27-35.

6. Green GE, Scott DA, McDonald JM, Woodworth GG, Sheffield VC, Smith RJ Carrier rates in the midwestern United States for GJB2 mutations causing inherited deafness. JAMA. 1999;281(23):2211-6.

7. Al-Qahtani MH, Baghlab I, Chaudhary AG, Abuzenadah AM, Bamanie A, Daghistani KJ, Safieh M, Fida L, Dallol A. Spectrum of GJB2 Mutations in a Cohort of Nonsyndromic Hearing Loss Cases from the Kingdom of Saudi Arabia. Genet Test Mol Biomarkers. 2009;23:23.

8. Snoeckx RL, Djelantik B, Van Laer L, Van de Heyning P, Van Camp G. GJB2 (connexin 26) mutations are not a major cause of hearing loss in the Indonesian population. Am J Med Genet A. 2005;135(2):126-9.

9. Sakuma N, Moteki H, Takahashi M, Nishio SY, Arai Y, Yamashita Y, Oridate $\mathrm{N}$, Usami SI. An effective screening strategy for deafness in combination with a next-generation sequencing platform: a consecutive analysis. J Hum Genet. 2016.

10. Atik T, Onay H, Aykut A, Bademci G, Kirazli T, Tekin M, Ozkinay F. Comprehensive Analysis of Deafness Genes in Families with Autosomal Recessive Nonsyndromic Hearing Loss. PLoS ONE. 2015;10(11), e0142154.

11. Hu J, Liu F, Xia W, Hao L, Lan J, Zhu Z, Ye J, Ma D, Ma Z. Exome sequencing identifies a mutation in TMC1 as a novel cause of autosomal recessive nonsyndromic hearing loss. J Transl Med. 2016;14(1):29.

12. Gu X, Guo L, Ji H, Sun S, Chai R, Wang L, Li H. Genetic testing for sporadic hearing loss using targeted massively parallel sequencing identifies 10 novel mutations. Clin Genet. 2015;87(6):588-93.

13. Tekin D, Yan D, Bademci G, Feng Y, Guo S, Foster 2nd J, Blanton S, Tekin M, Liu X. A next-generation sequencing gene panel (MiamiOtoGenes) for comprehensive analysis of deafness genes. Hear Res. 2016;333:179-84.

14. Landrum MJ, Lee JM, Benson M, Brown G, Chao C, Chitipiralla S, Gu B, Hart J, Hoffman D, Hoover J, et al. ClinVar: public archive of interpretations of clinically relevant variants. Nucleic Acids Res. 2016;44(D1):D862-8.

15. Xia JH, Liu CY, Tang BS, Pan Q, Huang L, Dai HP, Zhang BR, Xie W, Hu DX, Zheng $D$, et al. Mutations in the gene encoding gap junction protein beta-3 associated with autosomal dominant hearing impairment. Nat Genet. 1998; 20(4):370-3.

16. Rodriguez-Ballesteros M, Reynoso R, Olarte M, Villamar M, Morera C, Santarelli R, Arslan E, Meda C, Curet C, Volter C, et al. A multicenter study on the prevalence and spectrum of mutations in the otoferlin gene (OTOF) in subjects with nonsyndromic hearing impairment and auditory neuropathy. Hum Mutat. 2008:29(6):823-31.

17. Kurima K, Peters LM, Yang Y, Riazuddin S, Ahmed ZM, Naz S, Arnaud D, Drury S, Mo J, Makishima T, et al. Dominant and recessive deafness caused by mutations of a novel gene, TMC1, required for cochlear hair-cell function. Nat Genet. 2002;30(3):277-84.

18. Shafique S, Siddiqi S, Schraders M, Oostrik J, Ayub H, Bilal A, Ajmal M, Seco CZ, Strom TM, Mansoor A, et al. Genetic spectrum of autosomal recessive non-syndromic hearing loss in Pakistani families. PLoS ONE. 2014;9(6), e100146.

19. Sirmaci A, Duman D, Ozturkmen-Akay H, Erbek $S$, Incesulu A, Ozturk-Hismi B Arici ZS, Yuksel-Konuk EB, Tasir-Yilmaz S, Tokgoz-Yilmaz S, et al. Mutations in TMC1 contribute significantly to nonsyndromic autosomal recessive sensorineural hearing loss: a report of five novel mutations. Int J Pediatr Otorhinolaryngol. 2009;73(5):699-705.

20. Adato A, Weil D, Kalinski H, Pel-Or Y, Ayadi H, Petit C, Korostishevsky M, Bonne-Tamir B. Mutation profile of all 49 exons of the human myosin VIIA gene, and haplotype analysis, in Usher 1B families from diverse origins. Am J Hum Genet. 1997:61(4):813-21.

21. Exome Aggregation Consortium ML, Konrad K, Eric M, Kaitlin S, Eric B, Timothy F, Anne O'D-L, James W, Andrew H, Beryl C, Taru T, Daniel B, Jack K, Laramie D, Karol E, Fengmei Z, James Z, Emma P-H, David C, Mark DP, Ron D, Jason F, Menachem F, Laura G, Jackie G, Namrata G, Daniel H, Adam K, Mitja K, Ami Levy M, Pradeep N, Lorena O, Gina P, Ryan P, Manuel R, Valentin R-R, Douglas R, Khalid S, Peter S, Christine S, Brett T, Grace T, Maria T-L, Ben W, Hong-Hee W, Dongmei Y, David A, Diego A, Michael B, John D, Elosua R, Jose F, Stacey G, Gad G, Christina H, Sekar K, Markku L, Steven MC, Mark MC, Dermot MG, Ruth MP, Benjamin N, Aarno P, Shaun P, Danish S, Jeremiah S, Pamela S, Sullivan P, Jaakko T, Hugh W, James W, Mark D, Daniel MA. Analysis of protein-coding genetic variation in 60,706 humans. 2016.

22. Kuhn S, Johnson SL, Furness DN, Chen J, Ingham N, Hilton JM, Steffes G, Lewis MA, Zampini V, Hackney CM, et al. miR-96 regulates the progression 
of differentiation in mammalian cochlear inner and outer hair cells. Proc Natl Acad Sci U S A. 2011;108(6):2355-60.

23. Solda G, Robusto M, Primignani P, Castorina P, Benzoni E, Cesarani A, Ambrosetti U, Asselta R, Duga S. A novel mutation within the MIR96 gene causes non-syndromic inherited hearing loss in an Italian family by altering pre-miRNA processing. Hum Mol Genet. 2012;21(3):577-85.

Submit your next manuscript to BioMed Central and we will help you at every step:

- We accept pre-submission inquiries

- Our selector tool helps you to find the most relevant journal

- We provide round the clock customer support

- Convenient online submission

- Thorough peer review

- Inclusion in PubMed and all major indexing services

- Maximum visibility for your research

Submit your manuscript at www.biomedcentral.com/submit 